\title{
Optimizing the use of a "Zero-Gap" Gas Diffusion Electrode Setup for Electrochemical Reduction of $\mathrm{CO}_{2}$
}

Shima Alinejad ${ }^{a}$, Jonathan Quinson ${ }^{b}$, Yao Li ${ }^{c}$, Ying Kong ${ }^{a}$, Sven Reichenberger ${ }^{c}$, Stephan Barcikowski c, Peter Broekmann a, Matthias Arenz *a

a University of Bern, Department of Chemistry, Biochemistry and Pharmaceutical Sciences, Freiestrasse 3, 3012 Bern, Switzerland

b University of Copenhagen, Department of Chemistry, Universitetsparken 5, 2100 Copenhagen $\varnothing$, Denmark

c University of Duisburg-Essen, Technical Chemistry I and Center of Nanointegration DuisburgEssen (CENIDE), Universitätsstraße 7, Essen, North Rhine-Westphalia, 45141, Germany

*Corresponding Author

E-mail: matthias.arenz@unibe.ch

\begin{abstract}
The lack of a robust and standardized experimental test bed to investigate the performance of catalyst materials for the electrochemical $\mathrm{CO}_{2}$ reduction reaction $\left(\mathrm{ECO}_{2} \mathrm{RR}\right)$ is one of the major challenges in this field of research. To best reproduce and mimic commercially relevant conditions for catalyst screening and testing, gas diffusion electrode (GDE) setups attract a rising attention as an alternative to conventional aqueous-based setups such as the H-cell configuration. In particular a zero-gap design shows promising features for upscaling to the commercial scale. In this study, we develop further our recently introduced zero-gap GDE setup for the $\mathrm{CO}_{2} \mathrm{RR}$ using an $\mathrm{Au}$ electrocatalyst as model system and identify/report the key experimental parameters to control in the catalyst layer preparation in order to optimize the activity and selectivity of the catalyst.
\end{abstract}




\section{Introduction}

Climate change and the related rise in the average temperature on Earth is one of the main global concerns of the recent decades ${ }^{1}$. One of the major causes for climate change can be attributed to the rise in atmospheric carbon dioxide $\left(\mathrm{CO}_{2}\right)$ levels ${ }^{2}$. To tackle and significantly reduce $\mathrm{CO}_{2}$ emissions, society is chasing mitigation strategies such as switching to renewable energy sources and adopting electric and fuel cell vehicles. Beyond a mitigation strategy, using $\mathrm{CO}_{2}$ as a feedstock for $\mathrm{CO}_{2}$ reduction reaction $\left(\mathrm{CO}_{2} \mathrm{RR}\right)$ to fuels and value-added chemicals such as carbon monoxide (CO), formic acid, ethylene, ethanol, methane, and methanol became a widely-studied topic to add value to $\mathrm{CO}_{2}$ conversion ${ }^{3}$. One of the main challenges in the $\mathrm{CO}_{2} \mathrm{RR}$ field of research is the lack of a standard experimental setup and methodology to screen the performances of various catalytic materials identified as potential catalyst candidates to develop a $\mathrm{CO}_{2} \mathrm{RR}$ technology ${ }^{2}$. The various commonly-used screening methods for $\mathrm{CO}_{2} \mathrm{RR}$ can be divided into two main categories: aqueous-fed systems and gas-diffusion electrode (GDE) setups $^{4}$. Aqueous-fed systems such as the H-cell configuration, Figure 1-a, have the disadvantage of low solubility of $\mathrm{CO}_{2}$ which limits the $\mathrm{CO}_{2}$ conversion ${ }^{5,6}$. GDE setups can overcome this limitation by supplying a continuous stream of $\mathrm{CO}_{2}$ to the catalyst layer in order to sustain higher current densities. Going from an $\mathrm{H}$-cell to a GDE setup, the $\mathrm{CO}_{2}$ diffusion pathway to the surface of the catalyst will be reduced by roughly three orders of magnitude, from $\approx 50 \mu \mathrm{m}$ in an $\mathrm{H}$-cell to $\approx 50 \mathrm{~nm}$ in a GDE setup, which leads to the increase in maximum achieved current densities in GDE setups ${ }^{4}$. Despite these drawbacks, classical H-cell configurations are used for the majority $(>95 \%)^{7,8}$ of fundamental studies for $\mathrm{CO}_{2} \mathrm{RR}$ catalytic materials development and characterization ${ }^{4}$. Emerging screening methods for $\mathrm{CO}_{2} \mathrm{RR}$ based on 
GDE setups can be sub-divided into microfluidic designs, Figure 1-b, known as "Kenis-type" with a flowing catholyte $e^{9-11}$ and zero-gap electrolyzers ${ }^{5,8,12-14}$, Figure 1-c, where a gas diffusion layer $(G D L)$, catalyst and polymer exchange membrane are combined as one unit without presence of a liquid electrolyte separating the catalyst layer from the polymer exchange membrane. Therefore, zero-gap electrolyzers are also known as polymer electrolyte membrane (PEM) electrolyzers, catholyte-free, or gas-phase electrolyzers. The advantages of zero-gap electrolyzers over the microfluidic designs are multiple: it is relatively easy to pressurize the reactant and product flows, no product separation from the catholyte is required. In addition, the similarity of these devices to PEM water electrolyzers makes it easier to scale up to the commercial scale and construct the large sized stacks then required ${ }^{7}$. However, due to the lack of an electrolyte between the catalyst layer and polymer exchange membrane in zero-gap electrolyzers, this design suffers from $\mathrm{CO}_{2}$ reduction selectivity ${ }^{5,15}$. However, it has been reported that the selectivity problem in zero-gap electrolyzers can be promisingly mitigated in the presence of liquid electrolyte or water in the porous catalyst layer ${ }^{6}$.

Using gas diffusion layers on both electrodes of the reactor, Figure 1-d, in the same way as in membrane electrode assemblies (MEAs) for fuel cells, the $\mathrm{CO}_{2} \mathrm{RR}$ can be enhanced since a better distribution and higher pressure of $\mathrm{CO}_{2}$ can be reached due to the porous electrodes. Hence, an improved performance can be reached ${ }^{16,17}$. However, unlike the MEA design for fuel cells, where electrical power can be generated from a fuel, a high overpotential is essential for promoting the $\mathrm{CO}_{2} \mathrm{RR}$. 
a) H-cell configuration

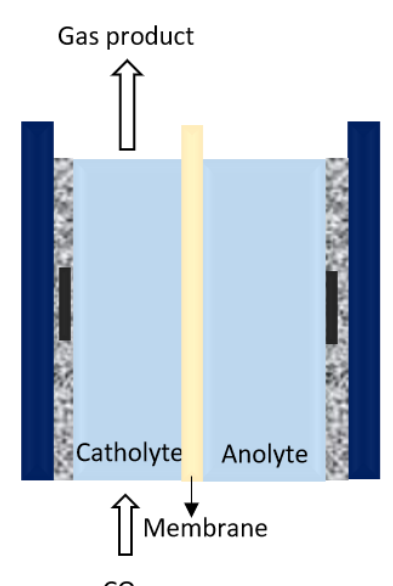

$\mathrm{CO}_{2}$ b) GDE Setup (microfluidic design)

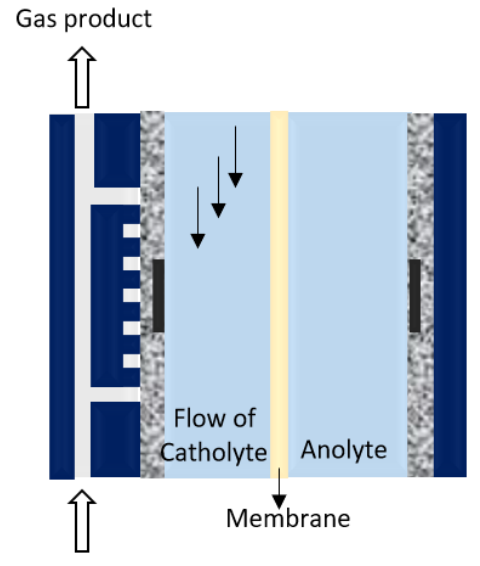

$\mathrm{CO}_{2}$ c) GDE Setup

(Zero-gap design)

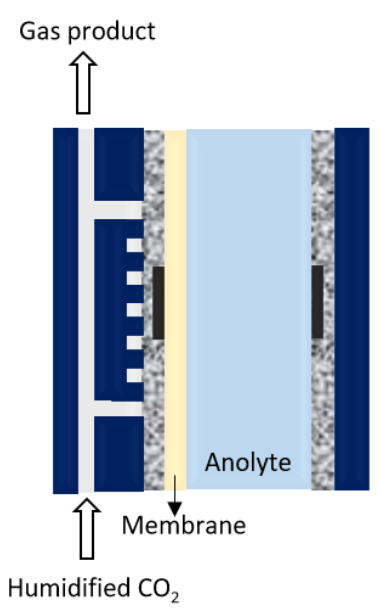

d) MEA design

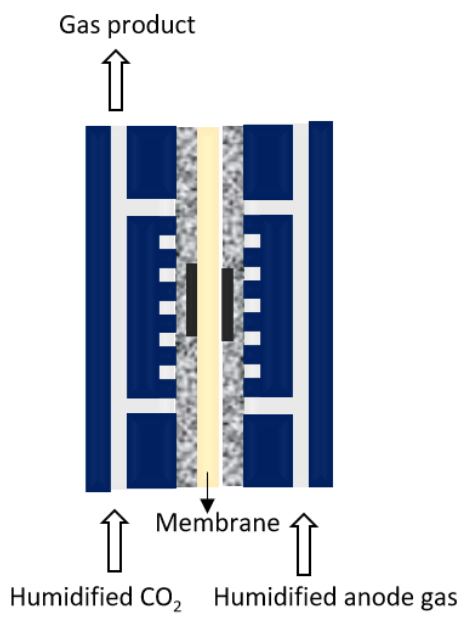

Figure 1. Schematic of commonly-used configurations for screening $\mathrm{CO}_{2} \mathrm{RR}$. (a) $\mathrm{H}$-cell configuration, (b) microfluidic design of GDE setup with a flowing catholyte channel, (c) zero-gap GDE setup with a non-flowing catholyte, and (d) MEA design.

In this study, we implemented our in-house developed GDE setup with a zero-gap half-cell design, to perform $\mathrm{CO}_{2}$ electrolysis on a standard gold $(\mathrm{Au})$ electrocatalyst. The benefits of this zero-gap GDE setup have previously been demonstrated in a screening of Au nanoparticle (NP) catalysts to study the selectivity and activity towards the $\mathrm{CO}_{2} \mathrm{RR}$ under industrially relevant current densities ${ }^{18}$. Gálvez-Vázquez et al. ${ }^{19}$ showed that in long term applications, limitations due to bicarbonate precipitations influence the selectivity. In this study, to isolate and identify the effects of using different screening setups on Au catalyst, we perform the same experiments in the GDE setup as well as in a H-cell configuration by holding all parameters constant. By optimizing parameters such as humidification, membrane, and supporting NPs onto carbon we could improve the activity and selectivity of the catalyst. The observations confirm that not only the $\mathrm{H}$-cell configuration suffers from mass transport limitations of the reactant gas, but also in such configuration one cannot differentiate between the influence of 
different ionomer contents in the catalyst layer: Selectivity and activity for samples with different ionomer contents are the same in an H-cell configuration. Probing the wettability of the catalyst surface with different ionomer contents by means of contact angle tests indicates that results of $\mathrm{CO}_{2}$ electrolysis in GDE setup is more meaningful than $\mathrm{H}$-cell measurements for potential applications in a reactor. Moreover, to reach an insight of the changes in Au NPs size as possible degradation mechanism(s), we perform small angel X-ray scattering (SAXS) which allows us to track particle size changes before and after $\mathrm{CO}_{2}$ electrolysis.

\section{Experimental}

\subsection{Preparation of 25 wt.\% Au Supported on Carbon (Au/C)}

$3 \mathrm{mg}$ of carbon Vulcan (XC72R, Fuel cell store) was added to $6.65 \mathrm{~mL}$ of ethanol (Ethanol absolute, VWR chemicals). After stirring for $5 \mathrm{~min}$ in the ultrasonic bath, the mixture was further dispersed using a horn sonicator (Q500, QSonica, 500watt, $20 \mathrm{kHz}$ ) with a pulse of $1 \mathrm{~s}$ working and $1 \mathrm{~s}$ resting for 10 min to achieve a homogenous carbon dispersion. In this study, we used surfactant free colloidal Au NPs with a size of ca. $8 \mathrm{~nm}$, which were synthesized based on a laser ablation method ${ }^{18}$. After adding $13.3 \mathrm{~mL}$ of the Au NPs colloidal suspension (1 mg of Au) to the carbon suspension, the mixture was stirred for $10 \mathrm{~min}$ by means of the horn sonicator. Finally, the glass vial containing the mixture was placed openly under a hood for solvent evaporation for around 5 days. After the first 24 hours, a black precipitation was observed on the bottom of the glass vial.

\subsection{Preparation of the Catalyst Ink}




\subsubsection{Unsupported Au NPs}

$13.3 \mathrm{~mL}$ of the unsupported Au NPs colloidal ( $1 \mathrm{mg}$ of $\mathrm{Au}$ ), and $2.6 \mu \mathrm{L}$ of the $10 \mathrm{wt} . \%$ Nafion ionomer (D1021, 10 wt.\% in $\mathrm{H}_{2} \mathrm{O}$, EW 1100, Fuel Cell Store) were mixed with $13.2 \mathrm{~mL}$ of isopropanol (IPA, 99.7+\%, Alfa Aesar). The glass vial containing the mixture was sonicated in the ultrasonic bath for $15 \mathrm{~min}$.

\subsubsection{5 wt.\% Supported Au on Carbon (Au/C)}

For the preparation of the catalyst ink, ultrapure Milli-Q water (resistivity $>18.2 \mathrm{M} \Omega \mathrm{cm}$, total organic carbon (TOC) < $5 \mathrm{ppb}$ ) from a Milli-Q system (Millipore) was used. $13.3 \mathrm{~mL}$ of IPA: Milli$\mathrm{Q}$ water (3:1, v:v) mixed solvent was added to a glass vial containing $4 \mathrm{mg}$ of $25 \mathrm{wt} . \% \mathrm{Au} / \mathrm{C}$. The glass vial containing the mixture was sonicated in the ultrasonic bath for $15 \mathrm{~min}$. For the preparation of the catalyst ink formulation of supported $\mathrm{Au} / \mathrm{C}$, different amounts of Nafion ionomer (D1021, 10 wt.\% in $\mathrm{H}_{2} \mathrm{O}$, EW 1100, Fuel Cell Store) and Anion ionomer (Sustainion XA-9 Alkaline lonomer 5\% in ethanol, Dioxide Materials) were used, Table 1.

\subsection{Preparation of the Catalyst Film}

For the catalyst film preparation, the same vacuum filtration setup was used as reported in our previous work ${ }^{18}$. In this setup, a cylindrical reservoir with a cross-sectional area of $1.76 \mathrm{~cm}^{2}$ was filled with $9.45 \mathrm{~mL}$ of the respective catalyst ink. Subsequently, a vacuum was applied by means of a Schlenk line pump thereby sucking the ink through a gas diffusion layer (GDL, H23C8 Freudenberg) which consisted of a macroporous (fibrous) layer and a microporous layer (MPL). Prior to filtration the GDL was positioned on a fritted glass filter. Thus, a homogenous catalyst layer was obtained, which was dried overnight in air. The nominal gold loading of the prepared 
Au films on the GDL, which we refer to as GDE, was $200 \mu \mathrm{g}_{\mathrm{Au}} \mathrm{cm}_{\mathrm{geo}}{ }^{-2}$. Prior to the catalyst film preparation the vacuum filtration setup was always soaked overnight in aqua regia solution followed by a gentle rinsing with water. In order to determine the real catalyst mass loading, the freshly prepared GDEs were subjected to an inductively coupled plasma-mass spectrometry (ICP-MS) analysis (Table 1). Technical details of this procedure are provided in in section 2.8. For the unsupported Au NPs, a particle loss during the vacuum filtration process was expected and confirmed by the ICP-MS analysis. It has also been observed that the presence of an ionomer in the catalyst ink leads to reduced particle losses during the catalyst film preparation. For all ionomer containing $\mathrm{Au} / \mathrm{C}$ GDE samples the measured mass loadings, measured by ICP-MS, indeed matched with their nominal loadings. However, for those Au/C GDE samples which have been prepared without ionomers there was a substantial discrepancy observed between the measured mass loadings and the expected values. In addition, the high uncertainty values indicate a catalyst film preparation which is less reproducible compared to those cases where the ionomer was present.

Table1. Different types of catalyst film and GDEs loading by ICP-MS.

\begin{tabular}{|c|c|c|c|c|c|}
\hline Catalyst & Ionomer & $\begin{array}{l}\text { Amount } \\
\text { of } \\
\text { ionomer } \\
\text { in the } \\
\text { ink }(\mu \mathrm{L})\end{array}$ & $\begin{array}{c}\text { Theoretical } \\
\text { loading } \\
\left(\mu \mathrm{g}_{\mathrm{Au}} \mathrm{cm}_{\mathrm{geo}^{-2}}\right)\end{array}$ & $\begin{array}{c}\text { Loading } \\
\text { based on ICP- } \\
\text { MS analysis } \\
\left(\mu \mathrm{g}_{\mathrm{Au}} \mathrm{Cm}_{\left.\mathrm{geo}^{-2}\right)}\right.\end{array}$ & Name in this paper \\
\hline $\begin{array}{c}\text { Unsupported } \\
\text { colloidal Au } \\
\text { NPs }\end{array}$ & Nafion & 2.6 & 200 & $50 \pm 1$ & $\begin{array}{l}50 \mu g_{A u} \mathrm{~cm}_{g e o^{-2}} \\
\text { Unsupported Au }\end{array}$ \\
\hline $\begin{array}{c}\text { Unsupported } \\
\text { colloidal Au } \\
\text { NPs }\end{array}$ & Nafion & 2.6 & 450 & $214 \pm 12$ & $\begin{array}{l}200 \mu g_{A u} \mathrm{~cm}_{g e o}^{-2} \\
\text { Unsupported Au }\end{array}$ \\
\hline $\begin{array}{c}25 \mathrm{wt} . \% \\
\text { Supported } \\
\mathrm{Au} / \mathrm{C}\end{array}$ & - & 0 & 200 & $143 \pm 34$ & $\mathrm{Au} / \mathrm{C}-\mathrm{No}$ ionomer \\
\hline
\end{tabular}




\begin{tabular}{|c|c|c|c|c|c|}
\hline $\begin{array}{c}25 \text { wt.\% } \\
\text { Supported } \\
\mathrm{Au} / \mathrm{C}\end{array}$ & Anion & 2.6 & 200 & $214 \pm 6$ & $\begin{array}{c}\text { Au/C-Low Anion } \\
\text { ionomer }\end{array}$ \\
\hline $\begin{array}{c}25 \text { wt.\% } \\
\text { Supported } \\
\mathrm{Au} / \mathrm{C}\end{array}$ & Nafion & 2.6 & 200 & $210 \pm 3$ & $\begin{array}{c}\text { Au/C-Low Nafion } \\
\text { ionomer }\end{array}$ \\
\hline $\begin{array}{c}25 \text { wt.\% } \\
\text { Supported } \\
\mathrm{Au} / \mathrm{C}\end{array}$ & Nafion & 28.3 & 200 & $190 \pm 5$ & $\begin{array}{c}\text { Au/C-High Nafion } \\
\text { ionomer }\end{array}$ \\
\hline
\end{tabular}

\subsection{Activation of Membranes}

For the activation of the anion exchange membrane, the membrane (Sustainion ${ }^{\circledR} \mathrm{X} 37-50$ Grade RT Membrane, with a dry thickness of $50 \mu \mathrm{m}$ thick, Dioxide Materials) was immersed in $1 \mathrm{M}$ $\mathrm{KOH}$ for $24 \mathrm{~h}$, and subsequently punched into circular pieces with a diameter of $2 \mathrm{~cm}$ by means of a sharp puncher. The punched and activated membranes were kept in $1 \mathrm{M} \mathrm{KOH}$. For the activation of the Nafion membrane, after punching circles with a diameter of $2 \mathrm{~cm}$ from a sheet of Nafion membrane (Nafion 117, $183 \mu \mathrm{m}$ thick, Fuel Cell Store), the punched membranes were treated for $30 \mathrm{~min}$ at $80{ }^{\circ} \mathrm{C}$ in $5 \mathrm{wt} . \% \mathrm{H}_{2} \mathrm{O}_{2}$, followed by 30 min at $80{ }^{\circ} \mathrm{C}$ in Milli-Q water and 30 min at $80{ }^{\circ} \mathrm{C}$ in 8 wt.\% $\mathrm{H}_{2} \mathrm{SO}_{4}$ solution. Between all treatments the membranes were rinsed thoroughly by Milli-Q water. The activated membranes were kept in a glass vial filled with MilliQ water. For both anion exchange and Nafion membranes, the activated membrane was gently rinsed with ultrapure Milli-Q water before assembling it into the GDE setup, and thereafter dried with precision wipes (Kimtech science).

\subsection{Preparation of GDE setup}


The employed GDE setup has already been described elsewhere ${ }^{19,20}$. For the preparation of the working electrode (WE), a GDL without an MPL with diameter of 2 cm (H23, $170 \mu \mathrm{m}$ thick @ 1MPa, Freudenberg), a GDL with an MPL (H23C8, $200 \mu \mathrm{m}$ thick @ 1MPa, Freudenberg) with a diameter of $2 \mathrm{~cm}$ and a circle hole of $3 \mathrm{~mm}$ in the center that was filled with the punched $\varnothing 3$ $\mathrm{mm} \mathrm{GDE}$, and an activated membrane $(\varnothing 2 \mathrm{~cm})$, respectively, were placed on top of the flow field, between the lower cell body (stainless steel) and the upper cell body (polytetrafluoroethylene (PTFE)), Figure 2-a. The activated membrane, which was placed on top of the GDE, separates the liquid electrolyte from the catalyst layer. Therefore, due to the lack of a flowing electrolyte between the catalyst layer and the ion- exchange membrane, this GDE setup configuration can be categorized as "zero-gap" or catholyte-free half-cell setup. With the help of a stainless-steel clamp, the upper and lower cell body were pressed together as shown in Figure 2-b. The PTFE upper cell body was filled with $15 \mathrm{~mL}$ of $2 \mathrm{M}$ potassium hydroxide solution $(\mathrm{KOH}, \mathrm{Merck}, \mathrm{pH} \approx 14)$. A gold wire and a silver/silver chloride electrode $(\mathrm{Ag} / \mathrm{AgCl}, 3 \mathrm{M}$ $\mathrm{KCl}$, VWR, double junction design) were used as the counter electrode (CE) and reference electrode (RE), respectively. To improve the reproducibility of the measurements, the CE was placed inside a separate compartment with a glass frit on the bottom, which is indicated as CE capillary. The cleaning of the cell was the same as described in our previous works ${ }^{21,22}$. For the humidification of the reactant gas, a glass bubbler filled with Milli-Q water was connected to the gas inlet of the lower cell body. During the electrolysis, a humidified $\mathrm{CO}_{2}$ stream (16 $\mathrm{mL} \mathrm{min}^{-}$ $\left.{ }^{1}\right)$ was continuously fed through the inlet of the GDE setup to transport the gaseous products from the outlet of GDE setup to the sample loop of the GC. 

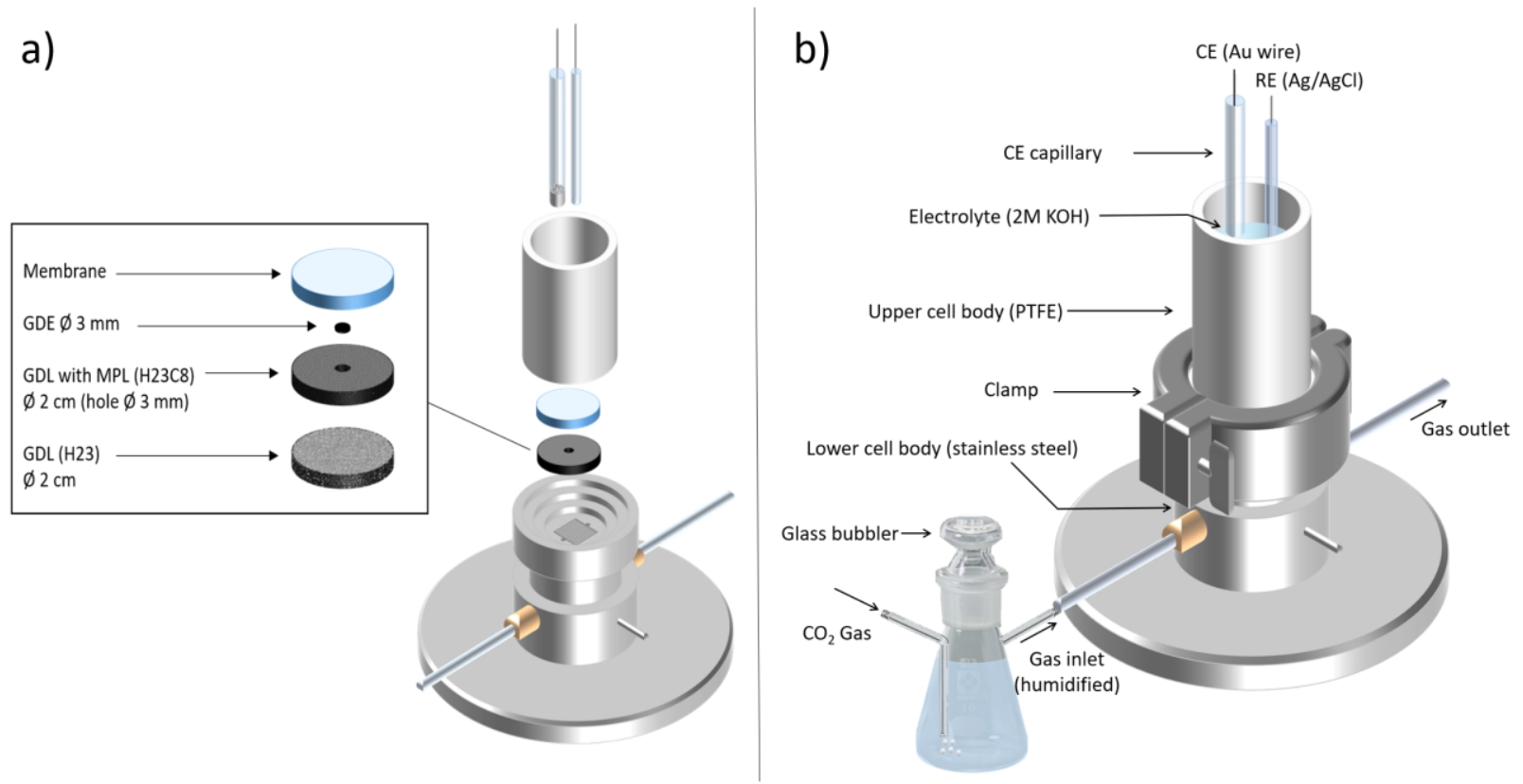

Figure 2. Sketch of the a) disassembled and b) assembled GDE cell employed in the present study.

\subsection{Assembly of the H-cell}

A home-made gas-tight $\mathrm{H}$-type glass cell was employed in this study, Figure 3 . The catholyte and the anolyte compartments were separated by means of a proton exchange membrane (Nafion 117, Sigma Aldrich). Both cathodic and anodic compartments were filled with $30 \mathrm{~mL}$ of $0.5 \mathrm{M}$ potassium bicarbonate $\left(\mathrm{KHCO}_{3}, \mathrm{ACS}\right.$ grade, Sigma-Aldrich, $\left.\mathrm{pH} \approx 7.2\right)$ electrolyte. Despite the fact that glassy carbon is the most common catalyst substrate in H-cell configurations, to avoid a catalyst substrate effect, we used a GDL as the catalyst substrate in the H-cell setup as in our previous work ${ }^{18}$. This enables a fair comparison between the results of GDE setup and the $\mathrm{H}$-cell setup. For the preparation of the WE for the $\mathrm{H}$-cell, a rectangular piece $(0.8 \mathrm{~cm} \times 3$ $\mathrm{cm})$ of a GDL with MPL (H23C8, $200 \mu \mathrm{m}$ thick @ 1MPa, Freudenberg) was used. The back side and the edges of the electrode were completely covered with Teflon tape in such a manner that 
only a circular area with diameter of $5 \mathrm{~mm}$ remained uncovered. A $\varnothing 5 \mathrm{~mm}$ GDE was punched and placed in the aforementioned exposed area. The described WE and a single junction $\mathrm{Ag} / \mathrm{AgCl}$ (saturated $\mathrm{KCl}$, Pine Research) as a RE were placed in the cathodic compartment. A Pt foil with a dimension of $0.8 \mathrm{~cm} \times 2 \mathrm{~cm}$ was placed in the anodic compartment as CE. Prior to the $\mathrm{CO}_{2}$ electrolysis, both cathodic and anodic compartments were saturated with $\mathrm{CO}_{2}\left(13 \mathrm{~mL} \mathrm{~min}^{-}\right.$ $\left.{ }^{1}\right)$ for $30 \mathrm{~min}$. The transport of gaseous products from the headspace of the catholyte to the sample loop of the $\mathrm{GC}$ was enabled by a continuous $\mathrm{CO}_{2}$ flow stream.

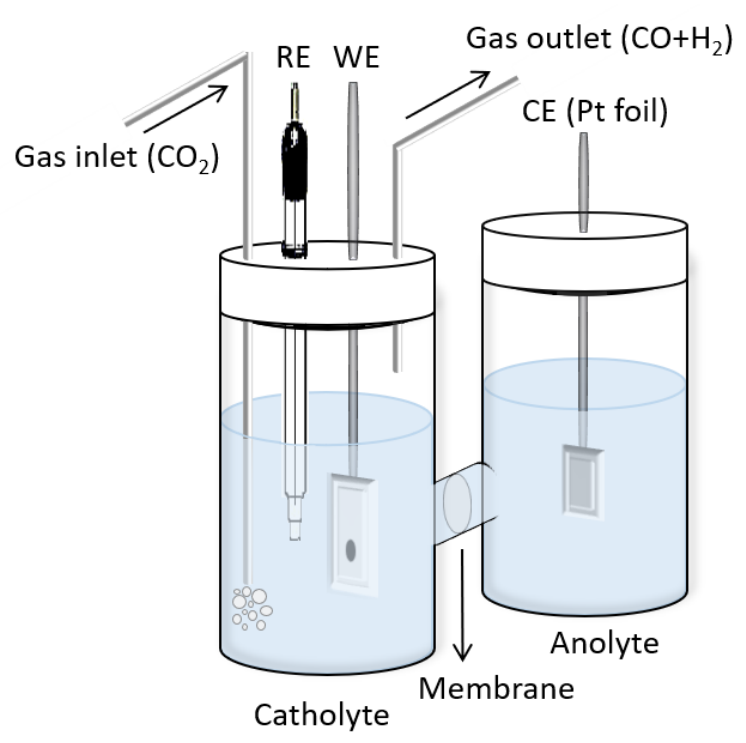

Figure 3. Sketch of the H-cell employed in the present study.

\section{7. $\mathrm{CO}_{2}$ electrolysis experiments}

Potentiostatic $\mathrm{CO}_{2}$ electrolysis experiments were carried out for $1 \mathrm{~h}$ at selected electrode potentials of $-0.4,-0.7$, and $-1.0 \mathrm{~V}_{\text {RHE. }}$. Every $10 \mathrm{~min}$ the analysis of the gaseous products was carried out by an online gas chromatograph (GC Model 8610C, SRI Instruments) which was triggered by the potentiostat and equipped with a thermal conductivity detector (TCD) and a flame ionization detector (FID) coupled to a methanizer to detect hydrogen and carbon 
monoxide, respectively. For preventing damages, the column of the GC, the outlet gas of the $\mathrm{CO}_{2} \mathrm{RR}$ was passed by a drying tube to remove the excess of water (Cole-Parmer Drierite, Fisher Scientific) before reaching the sample loop of the GC. The gas flow rate was monitored during the $\mathrm{CO}_{2}$ electrolysis by two flow meters (universal flow meter 7,000 GC by Ellutia) and (Q-Flow 140, FLQ-CTSS-BK-M, CONTREC AG). We used $\mathrm{H}_{2}$ (99.999\%), $\mathrm{CO}_{2}$ (99.999\%), and calibration standard gas from Carbagas (Switzerland) in the electrochemical measurements. For the sake of simplicity and easier comparison between the results of the GDE setup and H-cell measurements, all potentials in this study are converted to the RHE scale based using the following formula $E_{\mathrm{RHE}}=\mathrm{E}_{\mathrm{Ag} / \mathrm{AgCl}}+\mathrm{E}_{\mathrm{Ag} / \mathrm{AgCl}}^{0}+0.059 \times \mathrm{pH}$ (where all potentials are in volts, and

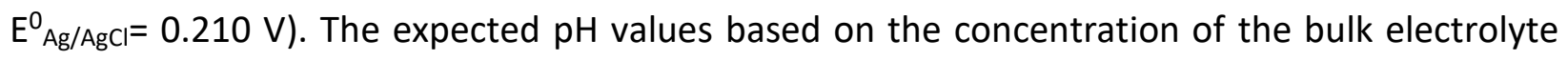
were used for RHE conversions. In the case of using non-concentrated electrolytes in GDE setup, the generation of hydroxide ions from water splitting during high-rate electrolysis will result in a significant change in electrolyte $\mathrm{pH}$ which causes the uncertainty of the actual $\mathrm{pH}$ at the electrode-electrolyte interface during operating conditions and shows the challenges related to the use of RHE scale ${ }^{4,11}$. Therefore, we changed the electrolyte from $0.5 \mathrm{M} \mathrm{KHCO}_{3}$ in the $\mathrm{H}$-cell to a highly concentrated electrolyte of $2 \mathrm{M} \mathrm{KOH}$ in the GDE setup to avoid the local $\mathrm{pH}$ deviation. Moreover, the uncompensated resistance between the WE and RE and the applied electrode potentials were monitored online using an AC signal ( $5 \mathrm{kHz}, 5 \mathrm{mV})$. In order to realize identical starting conditions for the electrolysis, a fresh WE was used for each experiment. The Faradaic efficiency (FE) for a given gaseous product i was determined based on equation (1): 


$$
F E_{i}=\frac{I_{i}}{I_{\text {total }}}=\frac{C_{i} \cdot \mathrm{V} \cdot F \cdot z}{10^{6} \cdot V_{m} \cdot I_{\text {total }}}
$$

where $\mathrm{I}_{\mathrm{i}}$ represents the partial current for the conversion of $\mathrm{CO}_{2}$ into product $\mathrm{i}, \mathrm{C}_{\mathrm{i}}$ its concentration in ppm measured by online GC using an independent calibration standard gas, $v$ the gas flow rate, $\mathrm{F}$ represents Faraday's constant, $\mathrm{z}$ the number of electrons involved in the formation of the particular product, $\mathrm{V}_{\mathrm{m}}$ the molar volume and $\mathrm{I}_{\text {total }}$ the total current at the time of the measurement.

\subsection{Inductively Coupled Plasma-Mass Spectrometry (ICP-MS)}

A $\varnothing 3$ circle of freshly prepared catalyst films (GDEs) were placed in a glass test tube. The test tube was kept in a water bath at $60{ }^{\circ} \mathrm{C}$ under vigorous stirring. Quickly after adding $5 \mathrm{~mL}$ of fresh aqua regia into the tube, the tube was closed for 1 hour with a help of a stopper. In this way, reaction of the hydrochloric acid $\left(\mathrm{HCl} 37 \%\right.$, Grogg chemie) and nitric acid $\left(\mathrm{HNO}_{3} 65 \%\right.$, Merk) in a ratio 4:1 in volume could take place inside the tube while the vapor was kept inside it to dissolve the Au NPs embedded on the GDE. The resulted solution was diluted by factors of 100, 50, and 30 with $3 \% \mathrm{HNO}_{3}$ and was then fed into a NExION 2000 ICP-MS instrument (PerkinElmer) to determine the Au mass loading of the electrodes.

\subsection{Small Angle X-ray Scattering (SAXS) Characterization}

The data were acquired at Swiss light sourc. Powder samples were sealed between two 5-7 $\mu \mathrm{m}$ thick mica windows and measurements. The general procedure for SAXS data preparation and measurements follow the approach detailed previously $\mathrm{REF}^{24}$. The measurements were 
performed directly on NP supported on carbon and a GDL material without Au NPs was used as background. The radially averaged intensity I(q) is given as a function of the scattering vector $q$ $=4 \pi \cdot \sin (\theta) / \lambda$, where $\lambda$ is the wavelength and $2 \theta$ is the scattering angle. The background corrected scattering data were fitted using a power law to take into account the behavior at low q value and a model of polydisperse spheres described by a volume-weighted log-normal distribution. The data were best fitted by adding a second model of polydisperse spheres also described by a volume-weighted log-normal distribution. In most cases tis second population is characterized by a large deviation and is probably accounting for the challenges in the background subtraction. In one case, for the sample Au/C- High Nafion ionomer the second population was very pronounced and is believed to actually represent larger size nanoparticles. The scattering data are fitted to the following expression:

$$
I(q)=A \cdot q^{-n}+C_{1} \cdot \int P_{s 1}(q, R) V_{1}(R) D_{1}(R) d R+C_{2} \cdot \int P_{s 2}(q, R) V_{2}(R) D_{2}(R) d R
$$

where $A \cdot q^{-n}$ corresponds to the power law while $A$ and $n$ are free parameters; $C_{1}$ and $C_{2}$ are scaling constants, $P_{s 1}$ and $P_{s 2}$ the sphere form factor, $V_{1}$ and $V_{2}$ the particle volumes, $D_{1}$ and $D_{2}$ the log-normal size distributions. The sphere form factor is given by:

$$
\operatorname{Ps}(q, R)=\left(3 \frac{\sin (q R)-q R \cos (q R)}{(q R)^{3}}\right)^{2}
$$

and the log-normal distribution by:

$$
\mathrm{D}(\mathrm{R})=\frac{1}{R \sigma \sqrt{2 \pi}} \exp \left(\frac{-\left[\ln \left(\frac{R}{R 0}\right)\right]^{2}}{2 \sigma^{2}}\right)
$$

where $\sigma$ is the variance and $R_{0}$ the geometric mean of the log-normal distribution.

The fitting was done using home written MATLAB code to optimize agreement between data and model available upon request. The free parameters in the model are: $A, n, R_{1}, R_{2}, C_{1}, C_{2}, \sigma_{1}$, 
$\sigma_{2}, C_{1}$ and $C_{2}$. The values obtained for these parameters are reported in Table $S X$ with the corresponding fits in Figure SX.

The average volume of nanoparticle from population 1 and from population $2,\langle\mathrm{~V}\rangle_{1}$ and $\langle\mathrm{V}\rangle_{2}$ respectively, lead to define volume fraction of population $1, \Phi_{\mathrm{V} 1}$, and volume fraction of population $2, \Phi_{\mathrm{V} 2}$, as:

$$
\begin{gathered}
\Phi_{\mathrm{V} 1}=\frac{\mathrm{N}_{1}<\mathrm{V}>_{1}}{\mathrm{~N}_{1}<\mathrm{V}>_{1}+\mathrm{N}_{2}<\mathrm{V}>_{2}}=1-\Phi_{\mathrm{V} 2} \\
\frac{\Phi_{\mathrm{V} 1}}{\Phi_{\mathrm{V} 2}}=\frac{\mathrm{N}_{1}<\mathrm{V}>_{1}}{\mathrm{~N}_{2}<\mathrm{V}>_{2}} \\
\frac{\mathrm{N}_{1}}{\mathrm{~N}_{2}}=\frac{\Phi_{\mathrm{V} 1}<\mathrm{V}>_{2}}{\Phi_{\mathrm{V} 2}<\mathrm{V}>_{1}}
\end{gathered}
$$

where $\mathrm{N}_{1}$ and $\mathrm{N}_{2}$ are the number of nanoparticles in the population 1 or 2 respectively.

From the SAXS data acquisition we have the relationship between the retrieved coefficient $C_{1}$ and $\mathrm{C}_{2}$ given by $\mathrm{C}_{\mathrm{i}}=\mathrm{k} . \Phi_{\mathrm{vi}} .\langle\mathrm{V}\rangle_{\mathrm{i}}$ where $\mathrm{i}=1$ or 2 and $\mathrm{k}$ is a constant.

$$
\begin{gathered}
\mathrm{k}=\frac{\mathrm{C}_{1}}{\Phi_{\mathrm{V} 1}<\mathrm{V}>_{1}}=\frac{\mathrm{C}_{2}}{\Phi_{\mathrm{V} 2}<\mathrm{V}>_{2}}=\frac{\mathrm{C}_{2}}{\left(1-\Phi_{\mathrm{V} 1}\right)<\mathrm{V}>_{2}} \\
\frac{\Phi_{\mathrm{V} 1}}{1-\Phi_{\mathrm{V} 1}}=\frac{\mathrm{C}_{1}<\mathrm{V}>_{2}}{\mathrm{C}_{2}<\mathrm{V}>_{1}} \\
\Phi_{\mathrm{V} 1}=\frac{1}{1+\frac{\mathrm{C}_{2}<\mathrm{V}>_{1}}{\mathrm{C}_{1}<\mathrm{V}>_{2}}}
\end{gathered}
$$

In order to weight the probability density function by the area or surface fractions we consider $<A>_{1}$ and $\left.<A\right\rangle_{2}$ as the average area of the nanoparticles from population 1 and 2 , respectively:

$$
\begin{gathered}
\Phi_{\mathrm{A} 1}=\frac{\mathrm{N}_{1}<\mathrm{A}>_{1}}{\mathrm{~N}_{1}<\mathrm{A}>_{1}+\mathrm{N}_{2}<\mathrm{A}>_{2}}=1-\Phi_{\mathrm{A} 2}=\frac{1}{1+\frac{\mathrm{N}_{2}<\mathrm{A}>_{2}}{\mathrm{~N}_{1}<\mathrm{A}>_{1}}} \\
\Phi_{\mathrm{A} 1}=\frac{1}{1+\frac{\Phi_{\mathrm{V} 2}<\mathrm{V}>_{1}<\mathrm{A}>_{2}}{\Phi_{\mathrm{V} 1}<\mathrm{V}>_{2}<\mathrm{A}>_{1}}} \\
\Phi_{\mathrm{A} 1}=\frac{1}{1+\frac{C_{2}\left(<\mathrm{V}>_{1}\right)^{2}<\mathrm{A}>_{2}}{C_{1}\left(<\mathrm{V}>_{2}\right)^{2}<\mathrm{A}>_{1}}}
\end{gathered}
$$




\subsection{Contact Angle Analysis}

Contact angles measurement was performed on a Krüss Advance Drop Shape Analyzer DSA25 (Krüss GmbH, Hamburg, Germany). Electrodes were mounted on a flat stage with the catalyst layer face-up. Sessile water drops (Milli-Q water) of $1.4 \mu \mathrm{L}$ were deposited at room temperature and the image was captured by the equipped CCD camera.

\section{Result and Discussion}

\subsection{Effect of the membrane}

To investigate the effect of the membrane on the selectivity and activity of the catalyst, we initially compared the use of a Nafion and an anion exchange membrane in the GDE setup performing 1-h $\mathrm{CO}_{2}$ electrolysis experiments with the unsupported Au catalyst at the same loading, Figure 3. To isolate the membrane effect, we held all other parameters constant. Using the Nafion membrane resulted in higher selectivity towards $\mathrm{CO}$ in the beginning of the $\mathrm{CO}_{2}$ electrolysis but a faster loss in CO selectivity over time. In addition, the total current density in the presence of the anion exchange membrane $\left(150 \mathrm{~mA} \mathrm{~cm}\right.$ geo $^{-2}$ in the beginning of the electrolysis) was roughly 50\% higher than when using a Nafion membrane $\left(100 \mathrm{~mA} \mathrm{~cm}_{\text {geo }}{ }^{-2}\right)$. Therefore, for all other measurements in this study, we used the anion exchange membrane in our zero-gap GDE setup. 

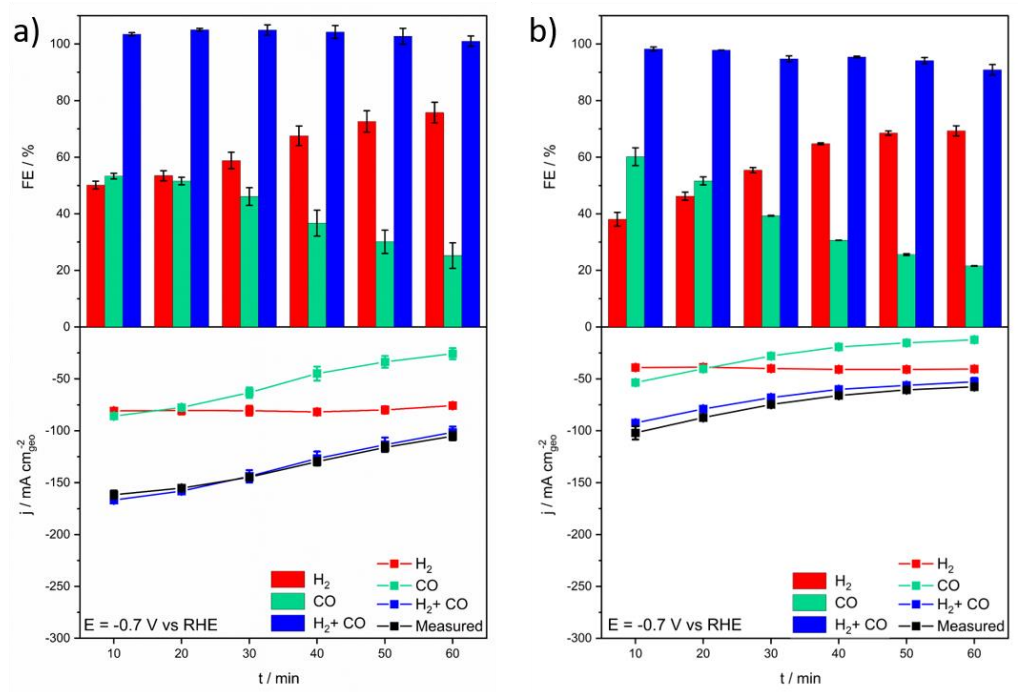

Figure 4. FEs and current densities of the gaseous products obtained from $\mathrm{CO}_{2} \mathrm{RR}$ on $50 \mu \mathrm{g}_{\mathrm{Au}} \mathrm{cm}_{\mathrm{geo}}{ }^{-2}$ of unsupported Au catalyst with a fresh a) anion exchange, and b) Nafion membrane, every 10 min of 1-hour $\mathrm{CO}_{2}$ electrolysis at $-0.7 \mathrm{~V}_{\mathrm{RHE}}$ in GDE setup. All indicated uncertainties are the standard deviation from three independent measurements.

\subsection{Effect of humidification}

To establish whether the CO selectivity deterioration in the GDE setup is due to a lack of humidification in this setup, we performed the following experiment. After 1-hour $\mathrm{CO}_{2}$ electrolysis on $50 \mu \mathrm{g}_{\mathrm{Au}} \mathrm{cm}_{\mathrm{geo}}{ }^{-2}$ of unsupported Au catalyst at $-0.7 \mathrm{~V}_{\mathrm{RHE}}$, the potential was kept at open circuit potential (OCP) for 30 min, while during this 30 min the humidified $\mathrm{CO}_{2}$ was purged continuously underneath of the catalyst layer, and afterwards again 1-hour $\mathrm{CO}_{2}$ electrolysis at $0.7 \mathrm{~V}_{\mathrm{RHE}}$ was performed, Figure 5 . It is seen that the selectivity performance after holding at OCP did not improved, indicating that the lower selectivity towards CO in the GDE setup might not be attributed to a lack of humidification. 


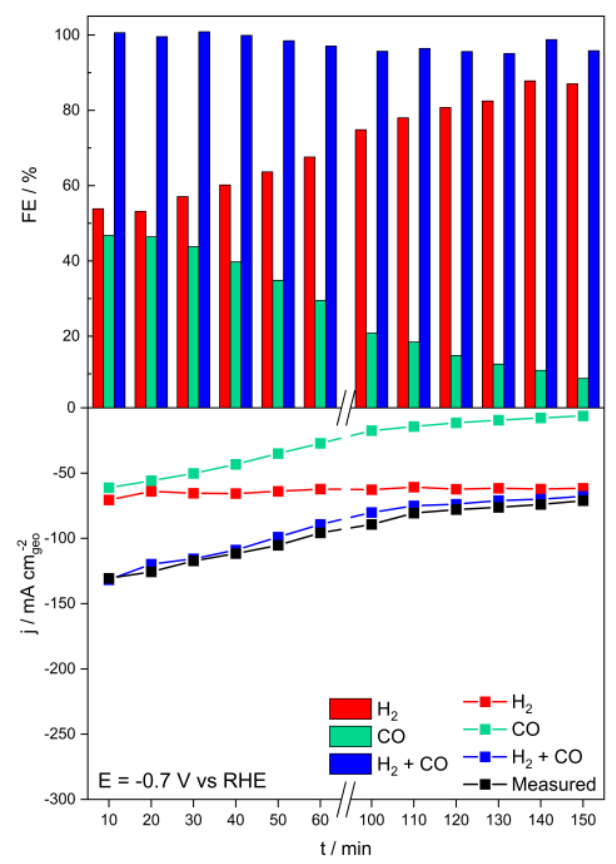

Figure 5. FEs and current densities of the gaseous products obtained from $\mathrm{CO}_{2} \mathrm{RR}$ on $50 \mu \mathrm{g}_{\mathrm{Au}} \mathrm{cm}_{\mathrm{geo}}{ }^{-2}$ of unsupported Au catalyst every 10 min of 2 rounds of 1-hour $\mathrm{CO}_{2}$ electrolysis at $-0.7 \mathrm{~V}_{\mathrm{RHE}}$ with an interval of $30 \mathrm{~min}$ at $\mathrm{OCP}$, in GDE setup.

\subsection{Source of instability}

Previous work with Ag NPs analyzing pristine and used catalyst particles by IL-SEM suggested that the observed CO selectivity deterioration in the GDE setup is not due to the catalyst itself (for instance if particle agglomeration or structural changes of the NP occurred) but rather by a degradation of the catalyst layer ${ }^{19}$. In the present work, we assumed three possible sources for the catalyst layer degradation over time, i) membrane instabilities, ii) the catalyst layer substrate, i.e., the GDL, and iii) degradation of Au NPs. In the following, we analyze all these three mentioned reasons for instability. In addition, for analyzing the degradation of Au NPs, we securitized different catalyst layers by SAXS instead of IL-SEM to obtain a more representative picture of the possible influences of the parameters on the NP size, the results are discussed at the end of the results and discussion section. 
To investigate potential influences of membrane instabilities during the $\mathrm{CO}_{2}$ electrolysis, we performed a 1-hour $\mathrm{CO}_{2}$ electrolysis experiment on $50 \mu \mathrm{g}_{\mathrm{Au}} \mathrm{cm}_{\mathrm{geo}}{ }^{-2}$ of unsupported Au catalyst, Figure 6-a, and after the experiment we introduced a new membrane into the cell while using still the same WE, Figure 6-b. As we did not observe any improvement in the performance, neither in activity nor in selectivity, we concluded that the degradation is mainly from the catalyst layer and not attributed to membrane degradation. In addition, we performed a 1-hour $\mathrm{CO}_{2}$ electrolysis on a blank $\mathrm{GDL}(\mathrm{H} 23 \mathrm{C} 8)$ at the same applied potential, Figure $\mathrm{S} 1$, to confirm that the catalyst substrate was not the source of the degradation and to demonstrate that the GDL did not oxidize at this applied potential and is therefore not the source of $\mathrm{CO}$ production.
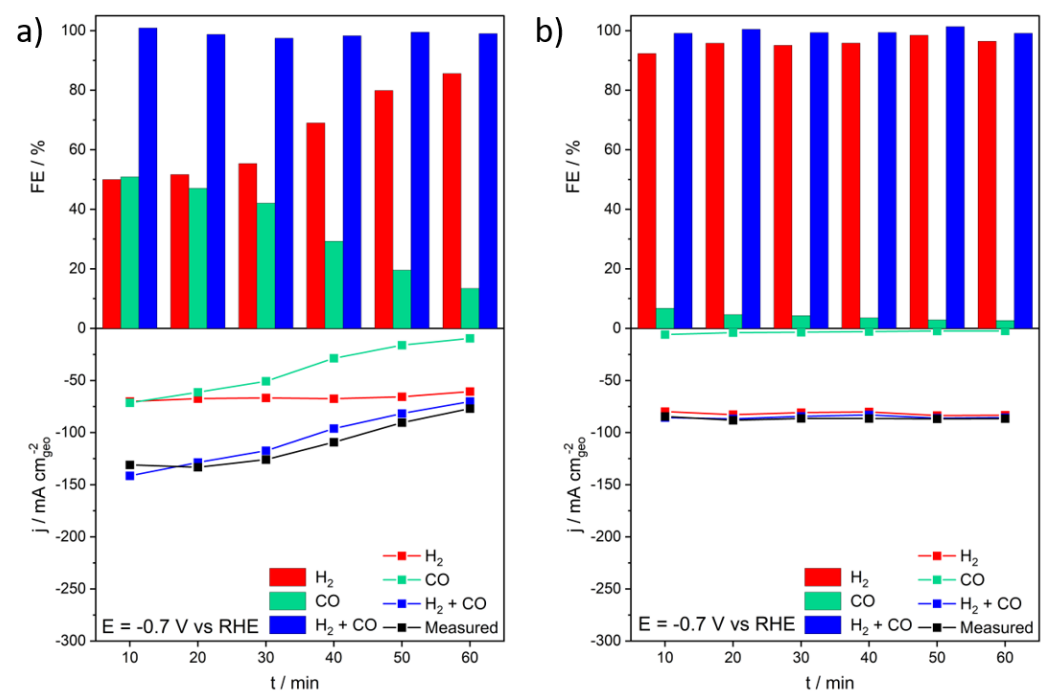

Figure 6. FEs and current densities of the gaseous products obtained from $\mathrm{CO}_{2} \mathrm{RR}$ on $50 \mu \mathrm{g}_{\mathrm{Au}} \mathrm{cm}_{\text {geo }}{ }^{-2}$ of a) unsupported Au catalyst with an Anion exchange membrane, b) same Au catalyst with a new fresh Anion exchange membrane every 10 min of 1-hour $\mathrm{CO}_{2}$ electrolysis at $-0.7 \mathrm{~V}_{\mathrm{RHE}}$ in $\mathrm{GDE}$ setup.

\subsection{Effect of intermediate layers in the membranes}

In addition to these tests the following experiment was conducted to test membrane effects further. In Figure 7-b, FEs and current densities of the gaseous products obtained from a 1-hour 
$\mathrm{CO}_{2}$ electrolysis at $-0.7 \mathrm{~V}_{\mathrm{RHE}}$ in the GDE setup on $50 \mu \mathrm{g}_{\mathrm{Au}} \mathrm{cm}_{\text {geo }^{-2}}$ of the unsupported Au catalyst are shown where $5 \mu \mathrm{L}$ of $0.5 \mathrm{M} \mathrm{KHCO}_{3}$ was drop casted between the catalyst film and the anion exchange membrane. It is seen that the $\mathrm{FE}_{\mathrm{co}}$ can be improved in presence of a solid-supported electrolyte adjacent to the catalyst film, which is in agreement with the work of Li et al. ${ }^{5}$ and Salvatore et al. ${ }^{6}$. Despite this improvement, we did not drop cast the $\mathrm{KHCO}_{3}$ on the catalyst layer for the rest of the experiments because the preparation of the cell in the presence of $\mathrm{KHCO}_{3}$ was quite challenging and it could lead to an irreproducible cell assembling procedure, limiting the valuable insight gained from using the GDE setup. If the work of Salvatore et al. ${ }^{6}$ indicates that including a solid-supported aqueous electrolyte layer might be necessary to achieve high CO selectivity, the exact role of this layer is still unclear. These same researchers furthermore shown that by replacing the solid-supported aqueous $\mathrm{NaHCO}_{3}$ layer with a solidsupported water layer, the $\mathrm{FE}_{\mathrm{co}}$ was comparable at all current density values up to $200 \mathrm{~mA}$ $\mathrm{cm}_{\text {geo }}{ }^{-2}$ in their GDE setup ${ }^{6}$. We confirmed this observation in our GDE setup by replacing $5 \mu \mathrm{L}$ of $0.5 \mathrm{M} \mathrm{KHCO}_{3}$ with water in a way that the anion exchange membrane used in the setup after rinsing was not fully dried. It was then observed that by replacing $\mathrm{KHCO}_{3}$ with water, the $\mathrm{FE}_{\mathrm{CO}}$ remained unchanged, see Figure 7-c. This result indicates that it is not $\mathrm{KHCO}_{3}$ that plays an essential role in the solid support layer performance, but water. It should be noted that in all three cases of dried anion exchange membrane, Figure 7-a, dried anion exchange membrane with $5 \mu \mathrm{L}$ of $0.5 \mathrm{M} \mathrm{KHCO}_{3}$ added between the catalyst and anion exchange membrane, Figure 7b, and applying a wet anion exchange membrane, Figure 7-c, the total current density did not change substantially. In all measurements an initial value of ca. $150 \mathrm{~mA} \mathrm{~cm}$ geo $^{-2}$ was achieved. Furthermore, it is shown in Figure S2, for the same experiments but for longer duration of $\mathrm{CO}_{2}$ 
electrolysis (2 hours) that the selectivity improvements only last for a limited period in the GDE setup.
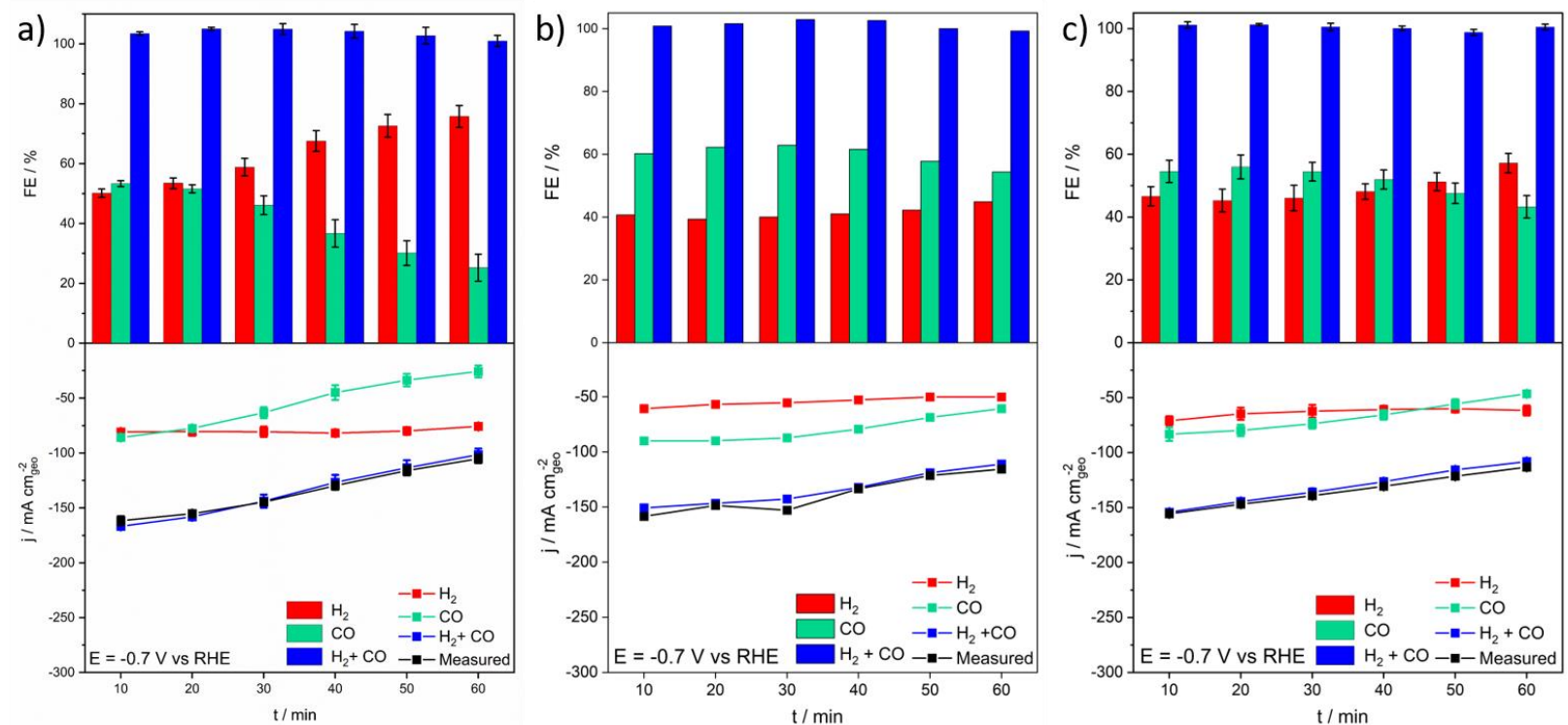

Figure 7. FEs and current densities of the gaseous products obtained from $\mathrm{CO}_{2} \mathrm{RR}$ on $50 \mu \mathrm{g}_{\mathrm{Au}} \mathrm{cm}_{\mathrm{geo}}{ }^{-2}$ of unsupported Au catalyst with a fresh a) dried anion exchange membrane, b) dried anion exchange membrane with $5 \mu \mathrm{l}$ of $0.5 \mathrm{M} \mathrm{KHCO}_{3}$ between the catalyst and anion exchange membrane, and c) wet anion exchange membrane, every 10 min of 1-hour $\mathrm{CO}_{2}$ electrolysis at $-0.7 \mathrm{~V}_{\mathrm{RHE}}$, in GDE setup. All indicated uncertainties are the standard deviation from three independent measurements.

\subsection{Influence of Au NP loading}

In the next step of this study, we increased the loading of the GDE film from $50 \mu \mathrm{g}_{\mathrm{Au}} \mathrm{cm}_{\mathrm{geo}}{ }^{-2}$ of unsupported Au catalyst to $200 \mu \mathrm{g}_{\mathrm{Au}} \mathrm{Cm}_{\mathrm{geo}^{-2}}$ and performed 1-h $\mathrm{CO}_{2}$ electrolysis measurements in both the GDE setup, Figure 8, and the H-cell configuration, Figure 9. In both setups, the absolute current density did not substantially increase by increasing the metal loading which could indicate an incomplete catalyst layer utilization. Indeed, in the GDE setup we even observed a decrease in current densities. This indicates that by increasing the metal loading, the accessibility of unsupported Au NPs becomes limited due to a compact catalyst layer. 
However, while the current densities did not increase, the selectivity towards CO was enhanced in both setups.
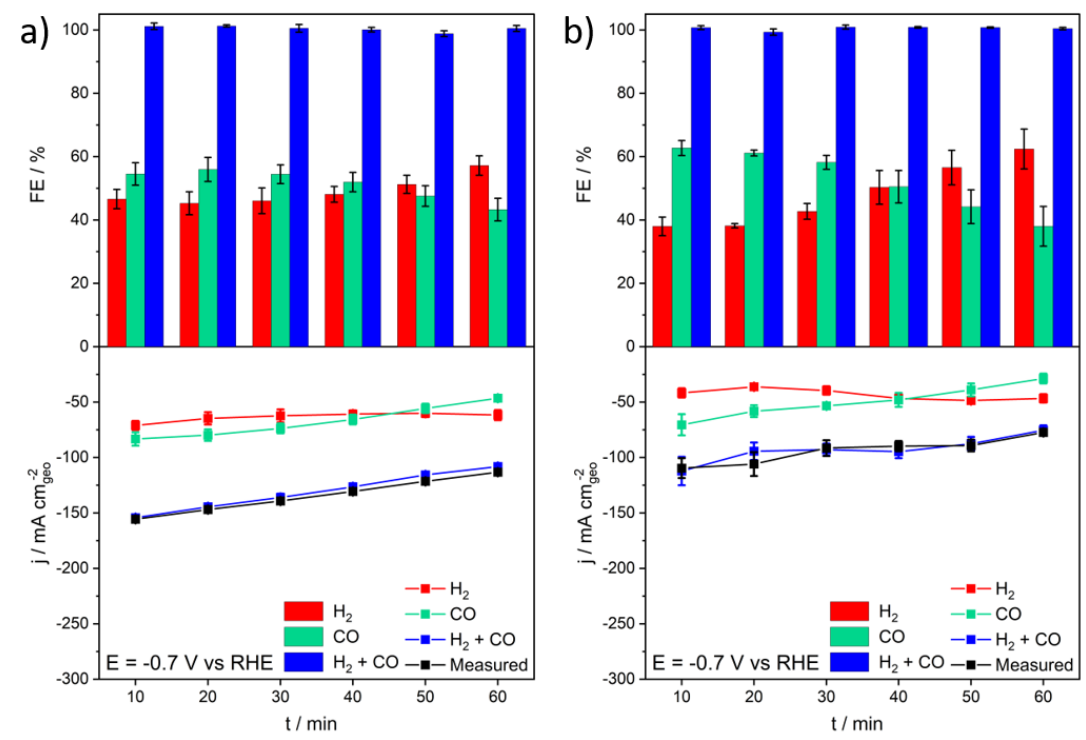

Figure 8. FEs and current densities of the gaseous products obtained from $\mathrm{CO}_{2} \mathrm{RR}$ on a) $50 \mu \mathrm{g}_{\mathrm{Au}} \mathrm{cm}_{\mathrm{geo}}{ }^{-2}$ and b) 200 $\mu \mathrm{g}_{\mathrm{Au}} \mathrm{cm}_{\mathrm{geo}}{ }^{-2}$ of unsupported Au catalyst, every $10 \mathrm{~min}$ of 1-hour $\mathrm{CO}_{2}$ electrolysis at $-0.7 \mathrm{~V}_{\mathrm{RHE}}$, in GDE setup. All indicated uncertainties are the standard deviation from three independent measurements.
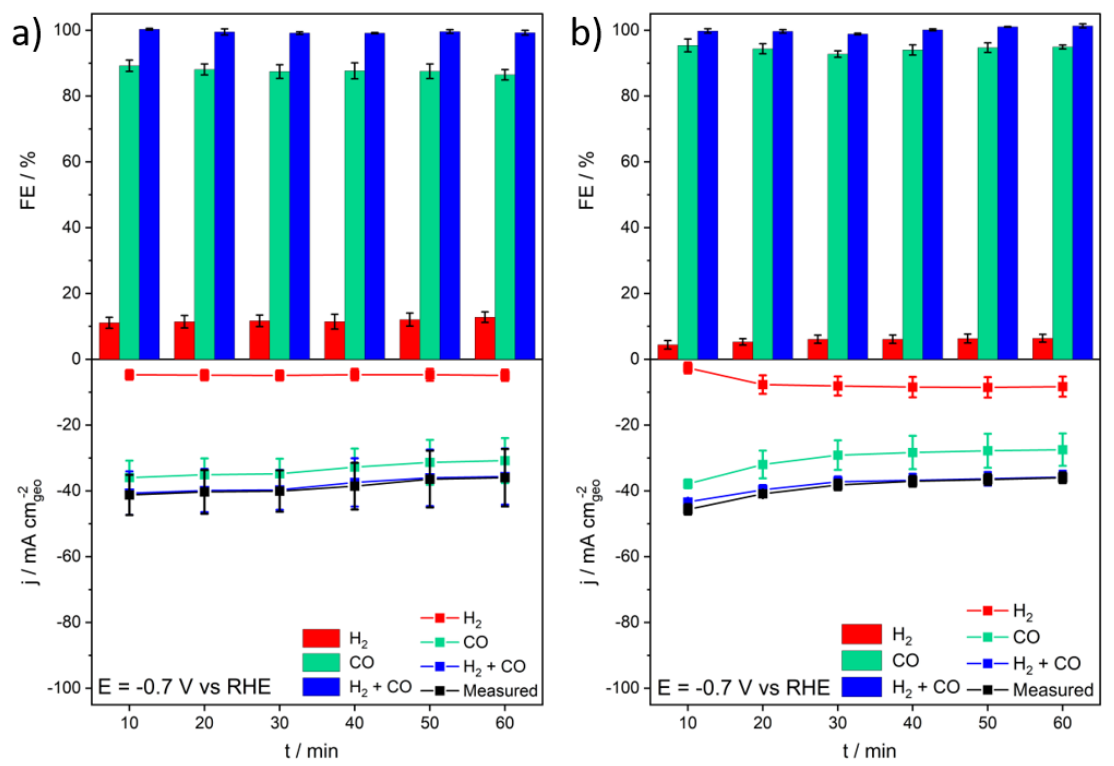

Figure 9. FEs and current densities of the gaseous products obtained from $\mathrm{CO}_{2} \mathrm{RR}$ on a) $50 \mu \mathrm{gAu}_{\mathrm{Au}} \mathrm{cm}_{\mathrm{geo}}{ }^{-2}$ and b) 200 $\mu \mathrm{g}_{\mathrm{Au}} \mathrm{Cm}_{\mathrm{geo}}{ }^{-2}$ of unsupported Au catalyst, every $10 \mathrm{~min}$ of 1 -hour $\mathrm{CO}_{2}$ electrolysis at $-0.7 \mathrm{~V}_{\mathrm{RHE}}$, in $\mathrm{H}$-cell configuration. All indicated uncertainties are the standard deviation from three independent measurements.

\subsection{Benefits of supported Au NPs / supported catalysts}


The results above clearly indicate limitations of unsupported catalyst layers. To be able to reach high current densities, it is required to load more accessible catalyst onto the GLD. For this purpose, we supported the Au NPs onto a Vulcan carbon support. Keeping the same amount of ionomer binder in the ink as for the unsupported Au catalyst (low Nafion ionomer content), we could significantly boost the performance of our catalyst, see Figure 10-a. Not only became the catalyst layer more active, but also the hydrogen evolution reaction (HER) became less favored. These results indicate that supporting of Au NPs onto carbon made the particles more accessible for the reaction.

\subsection{Effect of ionomer and ionomer amount on supported catalysts}

To investigate the supporting effect further, the ionomer content in the ink formulation was varied to a high amount (Au/C- High Nafion ionomer), completely eliminated (Au/C- No ionomer) and replaced by anion exchange ionomer (Au/C- Low Anion ionomer) as presented in Figure 10- b, c, and d, respectively. It is seen that by increasing the Nafion ionomer content, the catalyst layer became less active, the total current density decreased from 250 to $150 \mathrm{~mA}$ $\mathrm{cm}_{\text {geo }}{ }^{-2}$, and at the same time the parasitic HER became more favored increasing from $5 \%$ to $30 \%$ in $\mathrm{FE}$ at the beginning of the $\mathrm{CO}_{2}$ electrolysis. Also, in the case of a lack of ionomer, Figure 10-c), and by adding anion exchange ionomer, Figure 10-d, to the ink, the FE of the HER increased up to around $80 \%$, but also the total current density decreased substantially to ca. $100 \mathrm{~mA} \mathrm{~cm}_{\mathrm{geo}^{-2}}$. It is noteworthy that samples without ionomer exhibited a higher cell resistance (ca. $45 \Omega$ ) as compared to the samples with ionomer (ca. $20 \Omega$ ). This evidences a poor ionic conductivity of the catalyst film due to a lack of ionomer. For sake of completeness, in Figures S3-S6, the $\mathrm{CO}_{2}$ electrolysis on supported $\mathrm{Au} / \mathrm{C}$ in presence of different ionomer contents 
in the GDE setup is shown for different applied potentials, i.e., $-0.4,-0.7$, and $-1 V_{R H E}$ demonstrating that the observations have general character.
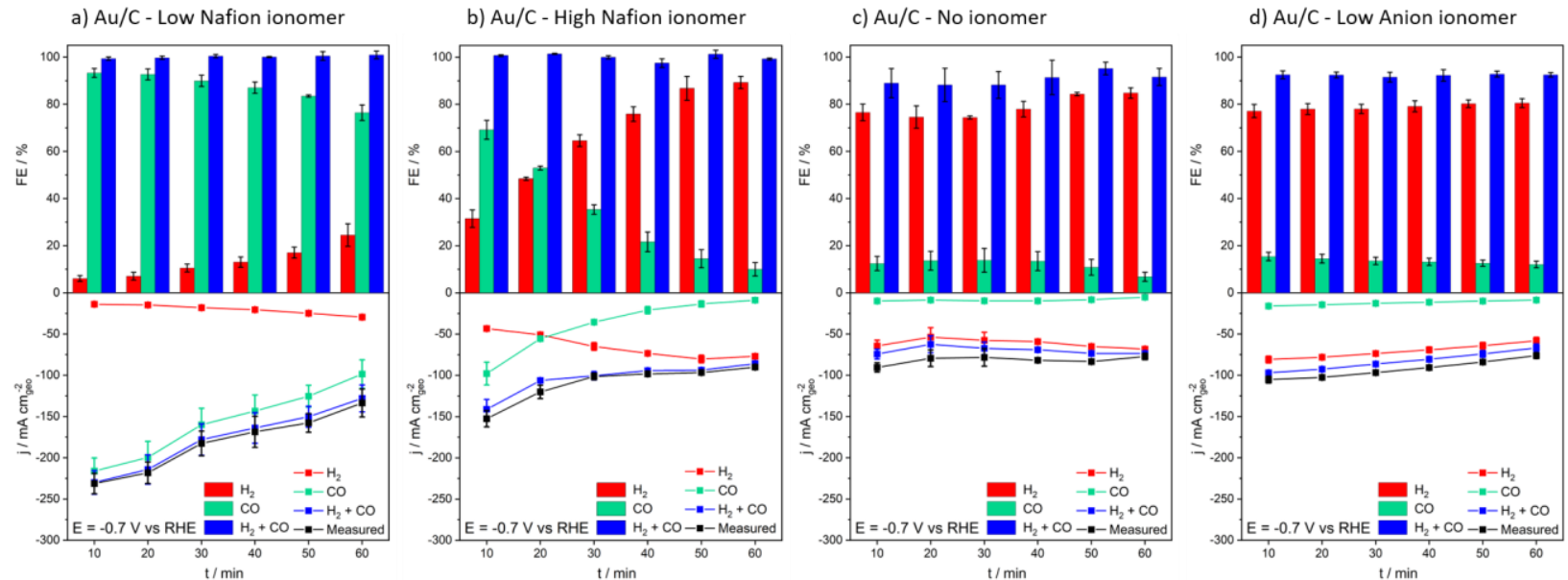

Figure 10. FEs and current densities of the gaseous products obtained from $\mathrm{CO}_{2} \mathrm{RR}$ on supported $\mathrm{Au} / \mathrm{C}$ catalyst with a) low Nafion ionomer, b) high Nafion ionomer, c) no ionomer, and d) low Anion ionomer every 10 min of 1-hour $\mathrm{CO}_{2}$ electrolysis at $-0.7 \mathrm{~V}_{\mathrm{RHE}}$, in GDE setup. All indicated uncertainties are the standard deviation from three independent measurements.

\subsection{Comparison with $\mathrm{H}$-cell}

Corresponding experiments conducted in the H-cell setup can be found in Figure S7. In H-cell setup in contrast to the GDE measurements, increasing the ionomer content leads to a slight increase in the total current density from 55 to $70 \mathrm{~mA} \mathrm{~cm} \mathrm{geo}^{-2}$, without affecting the HER FE, while in agreement to the GDE measurement, the total current density notably diminished to ca. $25 \mathrm{~mA} \mathrm{~cm}$ geo $^{-2}$ if no ionomer is used (the FE of the HER increases to $37 \%$ ). Finally, replacing Nafion with anion exchange ionomer, does not lead to substantial changes in catalyst performance. The results underline the importance of realistic reaction conditions for catalyst screening methods as those provided using a GDE setup. Indeed, in a GDE setup a clear 
influence of the ionomer used is observed whereas this influence is not probed in a $\mathrm{H}$-cell setup.

\subsection{Importance of wettability}

To further demonstrate the complexity of the ionomer effects and to argue further that these effects are at least partially related to a catalyst layer wetting effect, we performed contact angle measurements, see Figure 11. It should be thereby noted that albeit electrolysis conditions can cause electrocapillary forces, which will alleviate the surface contact angle under electric bias ${ }^{25}$, the electroless contact angle can still provide an overview of the wetting behavior of the catalyst layers ${ }^{26}$. Based on the surface contact angle result and assuming equal roughness (hydrophobicity and surface roughness determine the surface contact angle), we can rationalize the increase in the parasitic HER of the unsupported Au catalyst, and the supported $\mathrm{Au} / \mathrm{C}$ catalyst with no ionomer and low anion exchange ionomer by a changing in surface wettability from hydrophobic to hydrophilic. Hence, the selectivity deterioration towards $\mathrm{CO}$ ( $\mathrm{FE}_{\mathrm{CO}}$ ) of the unsupported $\mathrm{Au}$ catalyst, and the supported $\mathrm{Au} / \mathrm{C}$ catalyst with no ionomer and low Anion ionomer samples might at least partially attributed to the very hydrophilic behavior of the surface of these samples which leads to higher water adsorption ${ }^{26}$.

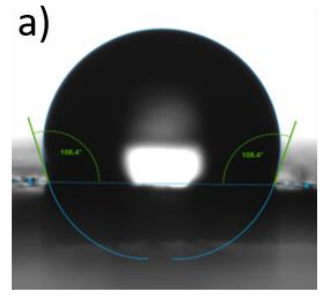

$108.4^{\circ}$

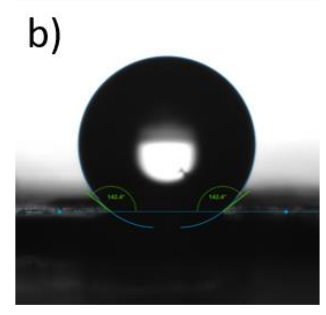

$142.4^{\circ}$

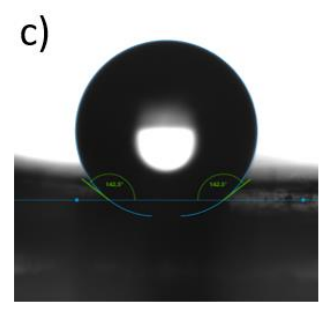

$142.5^{\circ}$ d)

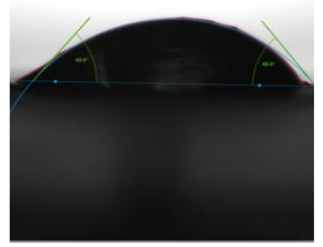

$49.0^{\circ}$ e)

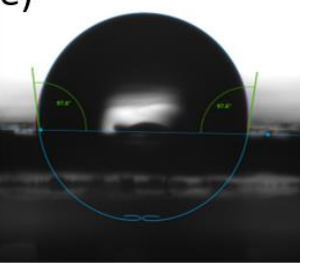

$97.6^{\circ}$

Figure 11. The surface contact angle images of as prepared a) unsupported Au NPs with low Nafion ionomer, and supported $\mathrm{Au} / \mathrm{C}$ catalyst with b) low Nafion ionomer, c) high Nafion ionomer, d) no ionomer, and e) low Anion ionomer on $\mathrm{GDL}$, before performing $\mathrm{CO}_{2}$ electrolysis. 
Finally, the SAXS analyses indicate that the average particle size of the supported Au/C NPs $(.2 \pm$ $2.1 \mathrm{~nm})$ is slightly larger than the unsupported Au NPs $(8.6 \pm 1.7 \mathrm{~nm})$, indicating slight agglomeration upon supporting, Table S1 and Figure S8. While the particle size after electrolysis remained the same for unsupported Au NPs, an increase in the average particle size from $8.2 \pm$ $\mathrm{nm}$ to $11.0 \pm \mathrm{nm}$ was observed for the $\mathrm{Au} / \mathrm{C}$ catalyst, see also Table S1. This observation agrees with the electrolysis measurements insofar as a decrease in total current density was observed for the Au/C catalyst, Figure 10-a, whereas the total current density of the unsupported Au NPs remained stable, Figure 8-b. Although these observations might lead to the conclusion that supporting Au NPs on Vulcan worsens the stability of the catalyst, it must be pointed out that at the same applied potential, the $\mathrm{Au} / \mathrm{C}$ catalysts still provides six times more current density than unsupported Au NPs. Interestingly, the increase in particle size under electrolysis conditions seems to depend on the ionomer in the catalyst layer. For Nafion ionomer a size increase is observed for low and high ionomer content, while the average particle size stays constant for an anion exchange ionomer, Figure S10 and Table 2.

Table 2. The average Au NPs diameter based on SAXS analysis.

\begin{tabular}{|c|c|c|}
\hline & Before $\mathrm{CO}_{2}$ electrolysis & After $\mathrm{CO}_{2}$ electrolysis \\
\hline $\mathrm{Au} N P s-$ Low Nafion ionomer & $8.6 \pm 1.7$ & $8.2 \pm 1.6$ \\
\hline $\mathrm{Au} / \mathrm{C}$ - Low Nafion ionomer & $9.2 \pm 2.1$ & $12.1 \pm 4.4$ \\
\hline $\mathrm{Au} / \mathrm{C}$ - High Nafion ionomer & $7.8 \pm 2.2$ & $20.7 \pm 8.6$ \\
\hline $\mathrm{Au} / \mathrm{C}$ - Low Anion ionomer & $12.1 \pm 3.7$ & $11.7 \pm 3.4$ \\
\hline
\end{tabular}

\section{Conclusion}


In this work, we systematically scrutinized the parameters to control in order to optimize the $\mathrm{CO}_{2} \mathrm{RR}$ performance of an Au catalyst layer in a zero-gap GDE setup. As opposed to a conclusion that would be drawn from a study performed in a $\mathrm{H}$-cell, the results presented here indicate that in GDE setups, the use of anion exchange membranes would lead to reach higher current densities for the same catalyst compare to the Nafion exchange membrane. Interestingly, this is not valid for the binder in the catalyst layer. Here a Nafion binder is favorable for the performance. Most importantly, it is shown that supported Au NPs lead to significantly higher current densities as compared to unsupported despite possible agglomeration effects in the supporting steps. This indicates that as in fuel cell catalyst layers, their porosity is essential for a full utilization. However, the application of supported catalysts might also lead to challenges. While the average particle size stays constant in the electrolysis of the layer of unsupported NPs, the SAXS analysis indicates a particle size increase for supported Au NPs. Interestingly, the increase in size depends on the ionomer type in the catalyst layer. The reasons for this observation can only be speculated, a ionomer dependent particle ripening might be related with different local pH. Finally, to optimize the "long term" performance of $\mathrm{Au} / \mathrm{C}$ catalyst layers it seems not only important to limit particle growth but a proper membrane humidification under operation is important to maintain. Most likely, this is related to potential cation/water crossover under operation that need to be transported out of the catalyst layer.

\section{Acknowledgment}

This work was supported by the Swiss National Science Foundation (SNSF) via the project

No. 200021_184742. Jonathan Quinson acknowledges the European Union's Horizon 2020 
research and innovation program under the Marie Skłodowska-Curie grant agreement No. 840523 (CoSolCat). The Niels Bohr Institute, University of Copenhagen, Denmark, is thanked for access to SAXS equipment, in particular J. K. K. Kirkensgaard

\section{References}

1. Oerlemans, J. Atmospheric science: Extracting a climate signal from 169 glacier records. Science (80-. ). 308, 675-677 (2005).

2. Jhong, H. R. M., Ma, S. \& Kenis, P. J. Electrochemical conversion of $\mathrm{CO} 2$ to useful chemicals: Current status, remaining challenges, and future opportunities. Curr. Opin. Chem. Eng. 2, 191-199 (2013).

3. Verma, S., Kim, B., Jhong, H. R. M., Ma, S. \& Kenis, P. J. A. A gross-margin model for defining technoeconomic benchmarks in the electroreduction of $\mathrm{CO} 2$. ChemSusChem $\mathbf{9}$, 1972-1979 (2016).

4. Burdyny, T. \& Smith, W. A. CO2 reduction on gas-diffusion electrodes and why catalytic performance must be assessed at commercially-relevant conditions. Energy Environ. Sci. 12, 1442-1453 (2019).

5. Li, Y. C. et al. Electrolysis of $\mathrm{CO} 2$ to Syngas in Bipolar Membrane-Based Electrochemical Cells. ACS Energy Lett. 1, 1149-1153 (2016).

6. Salvatore, D. A. et al. Electrolysis of Gaseous $\mathrm{CO} 2$ to $\mathrm{CO}$ in a Flow Cell with a Bipolar Membrane. ACS Energy Lett. 3, 149-154 (2018).

7. Endrődi, B. et al. Continuous-flow electroreduction of carbon dioxide. Prog. Energy Combust. Sci. 62, 133-154 (2017).

8. Weekes, D. M., Salvatore, D. A., Reyes, A., Huang, A. \& Berlinguette, C. P. Electrolytic CO2 Reduction in a Flow Cell. Acc. Chem. Res. 51, 910-918 (2018).

9. Gabardo, C. M. et al. Combined high alkalinity and pressurization enable efficient $\mathrm{CO} 2$ electroreduction to CO. Energy Environ. Sci. 11, 2531-2539 (2018).

10. Ma, S. et al. Carbon nanotube containing $\mathrm{Ag}$ catalyst layers for efficient and selective reduction of carbon dioxide. J. Mater. Chem. A 4, 8573-8578 (2016).

11. Lv, J. J. et al. A Highly Porous Copper Electrocatalyst for Carbon Dioxide Reduction. Adv. Mater. 30, 1-8 (2018).

12. Merino-Garcia, I., Alvarez-Guerra, E., Albo, J. \& Irabien, A. Electrochemical membrane reactors for the utilisation of carbon dioxide. Chem. Eng. J. 305, 104-120 (2016).

13. Lee, W., Kim, Y. E., Youn, M. H., Jeong, S. K. \& Park, K. T. Catholyte-Free Electrocatalytic CO2 Reduction to Formate. Angew. Chemie - Int. Ed. 57, 6883-6887 (2018).

14. Kutz, R. B. et al. Sustainion Imidazolium-Functionalized Polymers for Carbon Dioxide Electrolysis. Energy Technol. 5, 929-936 (2017).

15. C. Delacourt, P. L. Ridgway, J. B. K. and J. N. Design of an electrochemical cell making syngas $(\mathrm{CO}+\mathrm{H}-2)$ from $\mathrm{CO} 2$ and $\mathrm{H} 2 \mathrm{O}$ reduction at room temperature. J. Electrochem. Soc. 
155, B42-B49 (2008).

16. Pérez-Rodríguez, S., Barreras, F., Pastor, E. \& Lázaro, M. J. Electrochemical reactors for CO2 reduction: From acid media to gas phase. Int. J. Hydrogen Energy 41, 19756-19765 (2016).

17. Gutiérrez-Guerra, N., Moreno-López, L., Serrano-Ruiz, J. C., Valverde, J. L. \& de LucasConsuegra, A. Gas phase electrocatalytic conversion of $\mathrm{CO} 2$ to syn-fuels on $\mathrm{Cu}$ based catalysts-electrodes. Appl. Catal. B Environ. 188, 272-282 (2016).

18. Shima Alinejad, Jonathan Quinson, Gustav K. H. Wiberg, Nicolas Schlegel, D. Z. \& Yao Li, Sven Reichenberger, Stephan Barcikowski, M. A. Electrochemical Reduction of CO 2 on Au Electrocatalysts in a Zero-Gap, Half-Cell Gas Diffusion Electrode Setup: a Systematic Performance Evaluation and Comparison to a H-cell Setup Shima Alinejad. chemrxiv 1-28 (2021) doi:https://doi.org/10.33774/chemrxiv-2021-1t50s.

19. Gailvez-Vaìzquez, M. D. J. et al. Environment matters: CO2RR electrocatalyst performance testing in a gas-fed zero-gap electrolyzer. ACS Catal. 13096-13108 (2020) doi:10.1021/acscatal.0c03609.

20. De Jesús Gálvez-Vázquez, M. et al. Testing a Silver Nanowire Catalyst for the Selective CO2 Reduction in a Gas Diffusion Electrode Half-cell Setup Enabling High Mass Transport Conditions. Chimia (Aarau). 73, 922-927 (2019).

21. Alinejad, S. et al. Testing fuel cell catalysts under more realistic reaction conditions: accelerated stress tests in a gas diffusion electrode setup. J. Phys. Energy 2, 024003 (2020).

22. Alinejad, S., Quinson, J., Schröder, J. J., Kirkensgaard, J. J. K. \& Arenz, M. Carbonsupported platinum electrocatalysts probed in a gas diffusion setup with alkaline environment: How particle size and mesoscopic environment influence the degradation mechanism. ACS Catal. 13040-13049 (2020) doi:10.1021/acscatal.0c03184.

23. Quinson, J. et al. Surfactant-free synthesis of size controlled platinum nanoparticles: Insights from in situ studies. Appl. Surf. Sci. 549, (2021).

24. Schröder, J. et al. A New Approach to Probe the Degradation of Fuel Catalysts Under Realistic Conditions: Combining Tests in a Gas Diffusion Electrode Setup with Small Angle X-Ray Scattering. 1-20 (2020) doi:doi.org/10.26434/chemrxiv.12263804.

25. Schwaminger, S. P. et al. Potential-Controlled Tensiometry: A Tool for Understanding Wetting and Surface Properties of Conductive Powders by Electroimbibition. Anal. Chem. 90, 14131-14136 (2018).

26. Junge Puring, K. et al. Electrochemical CO2 Reduction: Tailoring Catalyst Layers in Gas Diffusion Electrodes. Adv. Sustain. Syst. 5, 1-13 (2021). 